\title{
Influence of Solids Concentration on Solid-Liquid Transportation in a Lime Production Plant
}

\author{
BEATA JAWORSKA-JÓŹWIAK \\ Faculty of Management and Computer Modelling \\ Kielce University of Technology \\ Al. Tysiąclecia P.P. 7, 25-314 Kielce \\ POLAND
}

\begin{abstract}
The main objective of the research is examining the influence of solids concentration on the shear stress and viscosity in fine-dispersive lime slurry collected from a flow installation existing in a selected processing plant producing lime. The analysis presented in the paper deals with slurry of average-size particles the diameter of which equals to $46 \mu \mathrm{m}$, solid density ranges from $1140 \mathrm{~kg} / \mathrm{m}^{3}$ to $1330 \mathrm{~kg} / \mathrm{m}^{3}$ and solids concentration by volume from $10.12 \%$ to $23.70 \%$. It has been shown that for solids concentration up to $18.28 \%$ by volume, the shear stress increases moderately with increasing concentration. If solids concentration is higher than $18.28 \%$ by volume, the shear stress increases exponentially. The determination of the boundary concentration above which the increase in shear stress is exponential is a fundamental guideline in determining the transport parameters of fine-dispersive lime slurry. The expected results of the analysis should be recommended for the transport of slurry with several times higher mass concentration and thus reducing the amount of water while increasing the economic profitability of the applied solution.
\end{abstract}

\section{Key-Words: Fine-dispersive lime slurry; slurry rheology; two-phase flow; lime production process}

Received: Maych 13, 2021. Revised: June 13, 2021. Accepted: June 25, 2021. Published: June 28, 2021.

\section{Introduction}

In recent years the need for stamping fine-dispersive slurry in industrial installations while increasing their solids concentration has become more important. Pumping such a slurry in pipelines requires the knowledge of its rheological properties, which mainly characterize the yield point and viscosity. These parameters significantly influence the friction losses during its flow through the pipeline. Available literature is focused on selected aspects of the slurry motion or is related to the specific types of slurry $[1,2]$.

Slurry transportation through pipelines is commonly used in mining and food industry $[3,4]$. It is well known that such a transportation requires attention to numerous problems, which mainly depend on a solid particle diameter and its size distribution, solids concentration and flow velocity $[5,6]$. The starting point in developing a pipeline characteristic is determining a slurry rheology, which mostly depends on solids concentration $[7,8]$. Other physical and chemical properties of a slurry, such as particle size distribution, shear rates, temperature etc. also have a significant influence on the slurry rheology, due to changes or modifications in the surface property $[9,10,11,12]$. Adequate understanding of a fluid's flow curve can significantly assist an engineering design process. Measurements of the flow curve under correct test conditions are the starting point for an equipment selection process. Rheometers are capable of measuring flow curves over a wide range of shear rate. However, for many process engineering applications, the relevant shear rate is typically about 1 to $1000 \mathrm{~s}^{-1}[13,14]$. Some slurries demonstrate nonNewtonian behaviour and a yield stress, which depends on solids concentration and solid density mainly, therefore a comprehensive rheology research for particular slurry existing in a lime production process and for different solids' concentration is presented in the paper. To determine a slurry rheology, three arbitrarily chosen rheological models were considered: Bingham, Casson and HerschelBulkley.

There are various methods of improving rheological properties of flowing slurries for economic and efficient transportation. Some researchers focus on preparing high concentration limestone slurry by manipulating the particle size distribution through blending fine-dispersive and coarse slurries in a fixed mass ratio. This treatment is used in order to obtain high solids concentration of the slurry with low viscosity $[9,15]$. Another method of reducing slurry viscosity during its transportation 
in a pipeline is chemical processing by applying suitable additives [16]. A sufficient dosage of such additives decreases the influence of a particle size on the flow ability of the slurry and increases its degree of dispersion [17].

The transport of fine-dispersive slurry occurring in a lime production process, described in the paper, requires pumping slurry obtained from a limestone rinsing process. Such a fine-dispersive slurry, called in the paper lime slurry, consists of fine solid particles, including mostly sand and dust fractions, as well as water serving as a carrier liquid [18]. In the final stage of the lime production process, lime slurry is directed to the sedimentation reservoir located $450 \mathrm{~m}$ away from the manufacturing plant. Unfortunately, the solids are transported with low solids concentration equal to $10.12 \%$ by volume. As a result, the production process requires a great amount of water and energy consumption to feed centrifugal pumps. Therefore, the paper presents a solution involving an increase of solids concentration during slurry transportation and pumping slurry with several times higher mass concentration. The expected results of the above - mentioned solution should be the reduction of operating costs of daily slurry transportation by reducing water and electricity consumption per unit weight of solid phase in the hydrotransport process.

The presented results of rheological studies illustrate the influence of solids concentration on the shear stress in slurries with three different solids concentration by volume.

\section{Physical Properties of the Tested Slurry}

Samples of slurry used in order to carry out the measurements were collected from a production plant and constitute a washing sludge, which is transported in the final stage of the lime production process. Such a slurry is treated as a waste product. The solid fraction in a slurry consists of small particles of quarried limestone containing a high percentage of calcium carbonate (about 73.6\%). Other chemical compounds found in the slurry are: $\mathrm{SiO}_{2}(13 \%), \mathrm{MgO}$ $(0.6 \%), \mathrm{Fe}_{2} \mathrm{O}_{3}(0.3 \%), \mathrm{Al}_{2} \mathrm{O}_{3}(1.1 \%)$ and $\mathrm{SO}_{3}(0.3 \%)$. Measured by a laser diffractometer, particle diameters of solids contained in a slurry ranged from $0.5 \mu \mathrm{m}$ to $163.5 \mu \mathrm{m}$. The measured average particle diameter of the tested sample equals to $46 \mu \mathrm{m}$. The results of the grain composition tests are presented in Figure1 in the form of a grain size distribution curve.

As the result of the granulometric analysis conducted in the tested slurry, the percentage contents of three grain fractions have been separated. The dust fraction (87.9\%) with an average grain diameter in the range of $(2 \div 50) \mu \mathrm{m}$ has the largest share in the tested sample. The clay fraction specifying particles with an average grain diameter less than $2 \mu \mathrm{m}$ constitutes $7.2 \%$ of all the particles. The particles determining the sand fraction and reaching an average grain diameter greater than $50 \mu \mathrm{m}$ constitute only $4.9 \%$ of all the particles contained in the slurry.

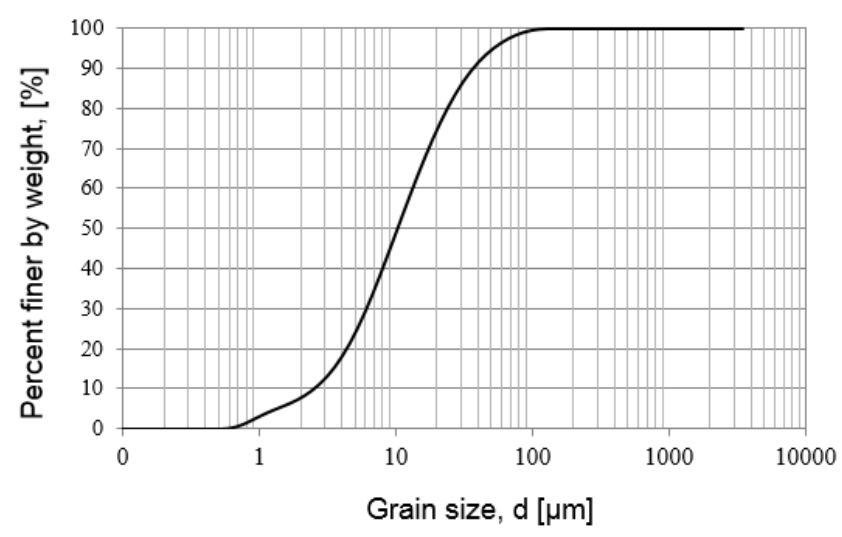

Fig.1 Grain size distribution curve of the tested slurry

Figure 2 presents the image of the lime slurry surface made by Scanning Electron Microscope Phenom Pro $X$ (SEM) with 500 magnifications after the application of $10 \mathrm{kV}$ electron-accelerating voltage.

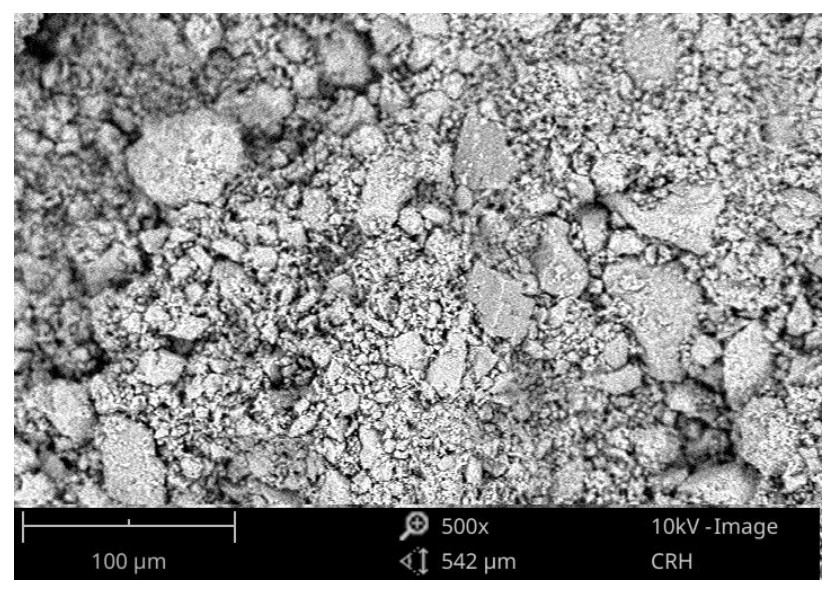

Fig.2 The Image of dried particles surface of the tested slurry

Figure 3 includes the results of the chemical microanalysis of the tested slurry made by energy dispersive X-ray spectroscopy in conjunction with SEM. 


\begin{tabular}{|c|c|c|c|}
\hline & Atomic percentage & & Certainty \\
\hline $\mathrm{O}$ & & $74.8 \%$ & 0.98 \\
\hline $\mathrm{Ca}$ & $19.5 \%$ & & 0.99 \\
\hline Al & $2.8 \%$ & & 0.96 \\
\hline Si & $2.7 \%$ & & 0.97 \\
\hline In & $0.3 \%$ & & 0.87 \\
\hline
\end{tabular}

Fig. 3 Chemical composition of the tested slurry

The density and viscosity for shear rate equal to $1000 \mathrm{~s}^{-1}$ as well as the Reynold's number obtained for the tested lime slurries in the studied range of solids concentrations are presented in Table 1.

Table 1. Parameters of lime slurry at different solids concentration

\begin{tabular}{cccc}
\hline $\mathrm{C}_{\mathrm{v}}$ & $\rho_{\mathrm{m}}$ & $\mu\left(\mathrm{dU} / \mathrm{dy}=1000 \mathrm{~s}^{-1}\right)$, & $\mathrm{Re}$ \\
{$[\%]$} & {$\left[\mathrm{kg} / \mathrm{m}^{3}\right]$} & {$[\mathrm{Pa} \cdot \mathrm{s}]$} & {$[-]$} \\
\hline 10.12 & 1140.11 & 0.00364 & 22958 \\
18.28 & 1254.49 & 0.00497 & 14880 \\
23.70 & 1330.40 & 0.00785 & 8402
\end{tabular}

\section{Experimental stand}

The main objective of the paper is to determine rheology of a particular slurry existing in a lime production process and to examine the solids concentration influence on the shear stress and viscosity.

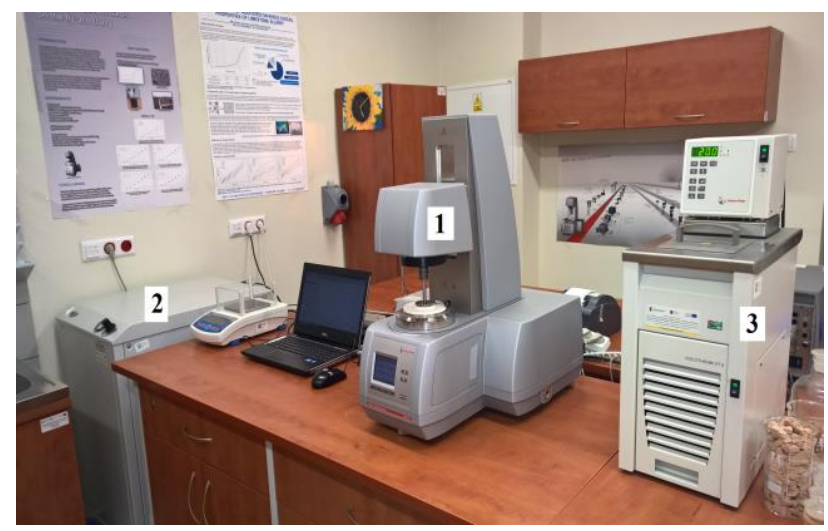

Fig.4 A General view of the test stand

Necessary experimental tests were conducted for lime slurry with three different solid concentrations by volume equal to $10.12 \%, 18.28 \%$ and $23.70 \%$. The measurements were carried out on a rotational viscometer, Anton Paar MCR 302, presented as (1) in Figure 4, which is a key device used to conduct experiments. A laboratory stand consists of supporting devices including a compressor (2) providing air supply and preventing damages of the viscometer's bearings, and a liquid circulator (3) used for temperature control by a thermostatic device and for counter-current cooling of the Peltier system. The air flow is controlled in order to obtain an optimal temperature distribution in the sample using the flow meter. Automatic temperature calibration sensors ensure constant values of the sample temperature. The collected measurement data are processed by means of the Rheoplus control software installed on the PC.

A system of coaxial cylinders with double measuring gap equal to $0.42 \mathrm{~mm}$ (internal) and $0.46 \mathrm{~mm}$ (external) was used to measure shear stress generated in the samples (Fig.5). This measuring system is dedicated for liquids with viscosity lower than $200 \mathrm{mPa} \cdot \mathrm{s}$ and ensures constant temperature distribution in the measurements duration. A sample is applied in the outer cylinder, which is a stationary element, while the inner cylinder (rotor) is driven by an engine. In the analysed device, a rotational speed is determined and the torque is measured by a viscometer. The torque is proportional to the current power supplying the engine and is converted into shear stress, meanwhile the rotational speed is converted into shear rate. In running experiments, the shear rate value was set by the operator of the viscometer, while the shear stress value was measured by the device.

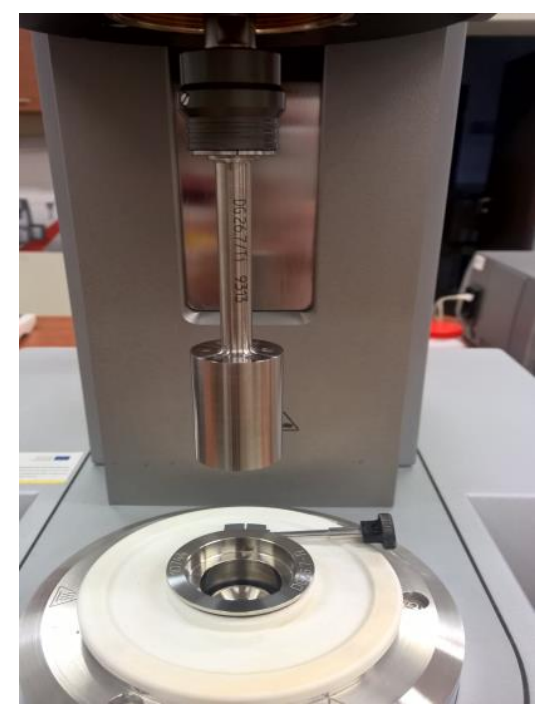

Fig.5 The measuring system adopted in experiments

In the adopted measuring system driven by the motor, the inner cylinder is immersed in the sample and forces the liquid to flow in the annular gap. The resistance of the shear fluid between the stationary and rotating boundary surfaces of the measuring system creates a viscosity-dependent torque on the 
inner cylinder and counterbalances the torque generated by the drive motor. A torque sensor (spring) is positioned between the drive motor and the inner cylinder shaft and twists as a result of the applied torque. The torsion angle of the torque spring is a direct measure of the viscosity of the sample.

\section{Method of research}

In order to determine volumetric solids concentration of the tested slurry, three samples underwent the process of vacuum drying. As a consequence, mass of liquid phase and mass of solid phase were defined, which allowed setting the percentage content of solid particles in the total weight of a slurry, as follows:

$$
C_{w}=\frac{m_{s}}{m_{s}+m_{l}} \cdot 100 \%
$$

where:

$\mathrm{C}_{\mathrm{w}}$ - solids concentration by weight in the slurry, $\%$

$\mathrm{m}_{1}$ - mass of carrier liquid, $\mathrm{kg}$

$\mathrm{m}_{\mathrm{s}}-$ mass of solids, $\mathrm{kg}$

The density of a slurry was calculated as follows:

where:

$$
\rho_{m}=\frac{m_{m}}{\frac{m_{S}}{\rho_{s}}+\frac{m_{m}-m_{S}}{\rho_{l}}}
$$

$\mathrm{m}_{\mathrm{m}}$ - mass of slurry, $\mathrm{kg}$

$\rho_{1}-$ density of carrier liquid, $\mathrm{kg} / \mathrm{m}^{3}$

$\rho_{\mathrm{m}}-$ density of slurry, $\mathrm{kg} / \mathrm{m}^{3}$

$\rho_{\mathrm{s}}-$ density of solids, $\mathrm{kg} / \mathrm{m}^{3}$

In equation (2), applying volumetric concentration of solids in the slurry, expressed as the ratio of solids volume in total volume of slurry, considering the density of slurry, can be expressed as follows:

$$
\rho_{m}=C_{v} \cdot\left(\rho_{s}-\rho_{l}\right)+\rho_{l}
$$

where:

$\mathrm{C}_{\mathrm{v}}$ - solids concentration by volume in the slurry, $\%$

Knowing the density of solids, equal to $2400 \mathrm{~kg} / \mathrm{m}^{3}$, and the density of lime slurry, the concentration of solid phase by volume in the slurry was calculated as follows:

$$
C_{v}=\frac{\rho_{m}-\rho_{l}}{\rho_{s}-\rho_{l}} \cdot 100 \%
$$

Viscometric measurements included one type of slurry but three different concentrations of solid phase equal to $10.12 \%, 18.28 \%$ and $23.70 \%$ by volume. To prevent particle sedimentation at low rotations of the inner cylinder, the test sample was subjected to preliminary mixing at the shear rate of $\mathrm{dU} / \mathrm{dy}=200 \mathrm{~s}^{-1}$ for a time equal to $10 \mathrm{~s}$. Then, the measurement was started with the maximum value of the shear rate of $1000 \mathrm{~s}^{-1}$. During the measurement, the rotor speed was diminished in leaps and bounds.

The measurements were carried out at $20^{\circ} \mathrm{C}$ for samples of $3.8 \mathrm{ml}$. The values of shear stress were measured in the range of shear rate from 0.1 to 1000 $\left[\mathrm{s}^{-1}\right]$.

\section{Experimental results}

The rheological data in terms of shear stress $(\tau)$ and shear rate (dU/dy) in a slurry with the concentration range from $10.12 \%$ to $23.70 \%$ by volume for chosen samples is plotted in Figure $6 a$, while Figure $6 b$ presents viscosity curves.
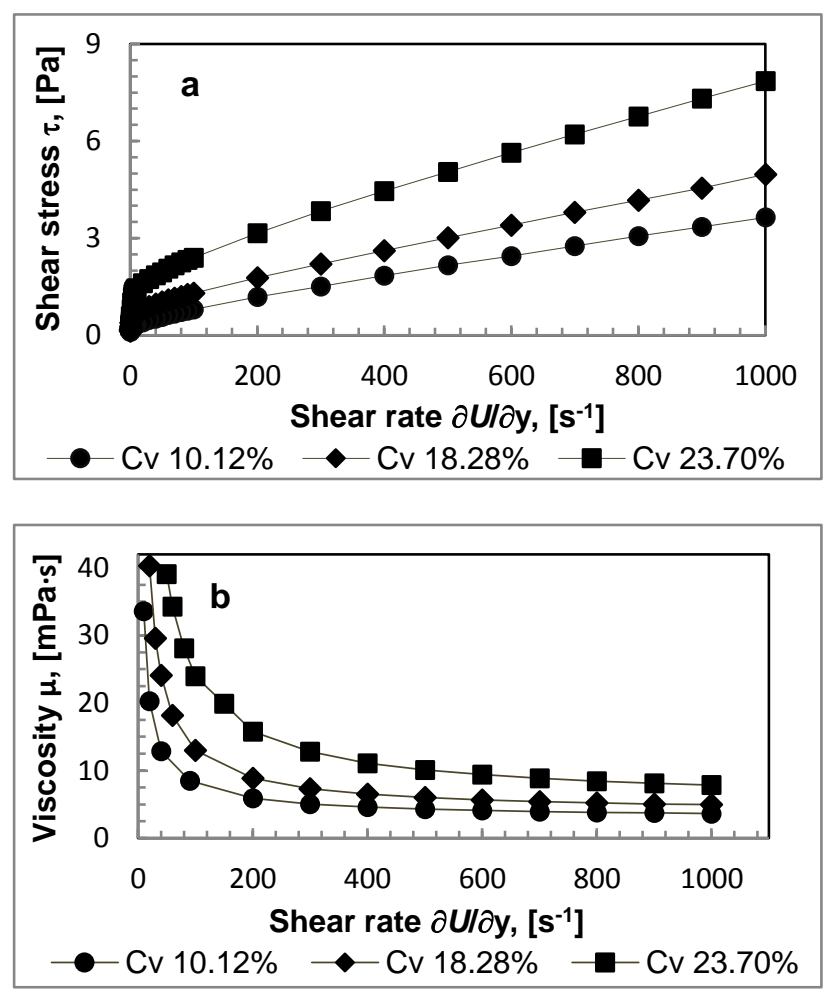

Fig.6 Flow curve (a) and viscosity curve (b) of the tested slurry for three different solids concentrations

The flow characteristic of lime slurry indicates a pseudoplastic behaviour, which is observed from the shape of flow curves and viscosity curves. The flow pattern is non-Newtonian for the tested solid concentrations. It is observed in Fig. 6a that the shear stress values increase with the increase of solids concentration and hence, the viscosity of the slurry increased with the increase of solids content in the lime slurry [19]. Pseudoplastic liquids are 
characterized by the decrease of viscosity with the increase in the form of shear rate (Fig. 6b). Technically, it means that for a given force or pressure, a larger mass flow can occur or the energy needed to maintain a given flow velocity can be reduced [20, 21].

Pseudoplastic liquids are usually described using the Herschel-Bulkley, Casson or Bingham rheological models [13, 22]. Table 2 presents equations of the chosen models used so that the experimental data obtained for the tested slurries could fit the selected mathematical models [23].

Table 2. Equations of selected rheological models describing plastic-viscous fluids flow

\begin{tabular}{|c|c|}
\hline $\begin{array}{c}\text { Flow curve } \\
\text { equation }\end{array}$ & $\begin{array}{c}\text { Apparent viscosity } \\
\text { equation }\end{array}$ \\
\hline \multicolumn{2}{|c|}{ The Bingham model } \\
\hline \multicolumn{2}{|c|}{$\eta_{\text {app }}=\frac{\tau_{0}}{\dot{\gamma}}+\eta_{p}$} \\
\hline \multicolumn{2}{|c|}{$+\eta_{p} \cdot \dot{\gamma}$} \\
\hline \multicolumn{2}{|c|}{ The Casson model } \\
\hline$\tau=\left\lfloor\tau_{0}^{\frac{1}{2}}+\left(\eta_{p} \cdot \dot{\gamma}\right)^{\frac{1}{2}}\right]^{2}$ & $\eta_{\text {app }}=\left[\left(\frac{\tau_{0}}{\dot{\gamma}}\right)^{1 / 2}+\left(\eta_{p}\right)^{1 / 2}\right]^{2}$ \\
\hline The Herschel-Bulkley model \\
\hline$\tau=\tau_{0}+k \cdot \dot{\gamma}^{n}$ & $\eta_{\text {app }}=\frac{\tau_{0}}{\dot{\gamma}}+k \cdot \dot{\gamma}^{n-1}$ \\
\hline
\end{tabular}

where $\tau$ is the shear stress, $\dot{\gamma}$ is the shear rate, $\eta_{\mathrm{p}}$ is plastic viscosity and $\tau_{0}$ is the yield stress

In a three-parameter Herschel-Bulkley model $k$ is the fluid consistency index and $n$ is the fluid behaviour index. The consistency index is an indication of the slurry viscosity and the behaviour index signifies shear thinning $(\mathrm{n}<1)$ or shear thickening ( $\mathrm{n}>1)$ behaviour [22]. Parameters $k$ and $n$ are determined on the basis of experimental data. According to the graphic interpretation of the equation, the slope of the straight line in the graph is equal to the value of the parameter $n$ and the ordinate value $\dot{\gamma}=1$ is equal to the $\log k[8,23]$.

We can observe the decrease in viscosity for the described slurries with the increase of shear rate, which means that the tested lime slurries are shear thinning.

The parameters of equations: the $\mathrm{R}^{2}$ coefficients and standard deviations (SD) related to shear stress; determining the compliance of the measurement results with the calculation results using the equations of the Bingham, Casson and HerschelBulkley models obtained for the tested lime slurries in the studied range of solids concentrations, are presented in Table 3 .

The $\mathrm{R}^{2}$ coefficients for the best fit of the tested slurries curves for the Herschel-Bulkley model were found in the range of $(92 \div 98) \%$. It was concluded that the Herschel-Bulkley model matched the experimental data at solids concentration of $18.28 \%$ and $23.70 \%$ very well. For lower solids concentration of slurry, equal to $10.12 \%$, the best fit of curves was obtained for the Casson rheological model $\left(\mathrm{R}^{2}=97 \%\right)$. Figure 4 presents the comparison of the experimental results with the data calculated using adopted rheological models for the analysed slurries in the form of flow curves for different solids concentration.

Presented in Table 3, yield stress values determined for slurries with the same solids concentration by volume differ depending on a selected rheological model. This results from the fact that the flow limit is not a physico-chemical parameter of the tested medium, but only a parameter

Table 3. Results of calculations made with the use of selected rheological models

\begin{tabular}{|c|c|c|c|c|c|c|c|c|c|}
\hline $\mathrm{C}_{\mathrm{v}},[\%]$ & \multicolumn{3}{|c|}{10.12} & \multicolumn{3}{c|}{18.28} & \multicolumn{3}{c|}{23.70} \\
\hline model & Bingham & Casson & H-B & Bingham & Casson & H-B & Bingham & Casson & H-B \\
\hline$\tau_{0},[\mathrm{~Pa}]$ & 0.12817 & 0.12015 & 0.06882 & 0.13761 & 0.16798 & 0.04588 & 0.28133 & 0.32975 & 0.09185 \\
\hline$\eta_{\mathrm{p},},[\mathrm{Pa} \cdot \mathrm{s}]$ & 0.00469 & 0.05393 & - & 0.00666 & 0.06847 & - & 0.01068 & 0.86788 & - \\
\hline $\mathrm{k},[-]$ & - & - & 0.09213 & - & - & 0.22857 & - & - & 0.04177 \\
\hline $\mathrm{n},[-]$ & - & - & 0.48207 & - & - & 0.40728 & - & - & 0.04023 \\
\hline $\mathrm{R}^{2}$ & 0.89292 & 0.97204 & 0.92015 & 0.78846 & 0.82899 & 0.95200 & 0.73957 & 0.76762 & 0.97676 \\
\hline $\mathrm{SD}$ & 0.33250 & 0.16992 & 0.28714 & 0.61611 & 0.55394 & 0.29346 & 1.09350 & 1.03300 & 0.32665 \\
\hline
\end{tabular}


of the model describing the flow curve of the tested slurry in a specific range of shear rate.

Shown in Table 3, values of parameter $n$ for the equations described by using the Herschel-Bulkley's model decrease with the increase of solids concentration of lime slurry. For the examined slurry samples, the value of the flow coefficient $n$ is respectively 0.48207 and 0.40728 for slurry with solids concentration by volume equal to $10.12 \%$ and $18.28 \%$. For slurry with the highest solids concentration by volume equal to $23.70 \%$, the $n$ parameter assumes 0.04023 . Such values of the parameter $n$ indicate strongly non-Newtonian fluids properties.

The value of the standard deviation (SD) determines the difference between the values predicted by a selected rheological model shear stresses and the values obtained from the experiment.

Presented in Fig. 7, compliance of the measurements of shear stress with the predictions described by selected rheological models confirm the conclusions drawn from the analysis of the $\mathrm{R}^{2}$ coefficients value. From the three selected rheological models describing plastic-viscous fluids flow for slurries with the yield stress point, the results received for the Herschel-Bulkley's rheological model are characterized by the highest compliance with the experimental data for samples of slurry with solids concentration by volume equal to $18.28 \%$ and $23.70 \%$. Symultaneously, for slurry of solids concentration by volume equal to $10.12 \%$ the highest compliance with the experimental data is obtained for the Casson rheological model. The results of the conducted measurements allowed determining the yield stress, below which the sample behaves like a solid of infinitely high viscosity. A network of intermolecular interactions occur at rest (among others polar interactions and interactions determined by the Van der Waals forces), which limits the possibility of changing the position of its volumetric elements. If the external forces are weaker than forces supporting the intermolecular interaction network, the sample deforms only elastically. When the external forces are strong enough to overcome the forces of intermolecular interactions, the network of interactions disappears. It happens when the shear stresses exceed the yield point. Volumetric elements of the sample change the position irreversibly and the sample begins to flow [25].

\section{Discussion}

The rheological behaviour of lime slurry originating from lime production process was investigated. The results of the conducted experimental studies for slurries of solids concentration equal to $10.12 \%$, $18.28 \%$ and $23.70 \%$ indicated the pseudoplastic shear thinning behaviour. Several rheological models were considered in order to achieve the best fit of measurements. However, the best results were obtained by adopting the Herschel-Bulkley and Casson rheological models.

The influence of solids concentration on slurry rheology is significant since various range of solids concentration can lead to different types of flow curves. Each of the tested sample reveals a pseudoplastic character with a definite yield stress. The degree of its pseudoplasticity increases with increasing solids concentration. For slurry with low solids concentration $\left(\mathrm{C}_{\mathrm{v}}=10.12 \%\right)$ and at lower shear rate, the interparticle distance is large enough. Therefore, lime particles are not subjected to the attractive van der Waals forces between one another, but move freely as individuals [26]. At higher solids concentrations $\left(\mathrm{C}_{\mathrm{v}}=18.28 \%\right.$ and $\left.23.70 \%\right)$, the interactions between lime particles take place as a result of smaller interparticle distances in a denser slurry. At higher range of shear rate, shearing forces break down the formation of flocks and ensure more flow fluency [27].

The predicted results of shear stresses and viscosity by the Herschel-Bulkley rheological model demonstrate a good consistence with experimental data in the range of shear rate from $1 \mathrm{~s}^{-1}$ to $500 \mathrm{~s}^{-1}$ for slurry with solids concentration equal to $\mathrm{C}_{\mathrm{v}}=18.28 \%$, and from $1 \mathrm{~s}^{-1}$ to $600 \mathrm{~s}^{-1}$ for slurry with solids concentration equal to $23.70 \%$ by volume. This leads to the conclusion that the best fit of the measured data can be achieved by using the Herschel-Bulkley's rheological model if lime slurry of solids concentration higher than $18.28 \%$ is considered in the wide range of shear rates. For slurry with lower solids concentration, equal to $\mathrm{C}_{\mathrm{v}}=10.12 \%$, the best consistence of shear stresses and viscosity with experimental data in the range of shear rate from $1 \mathrm{~s}^{-1}$ to $400 \mathrm{~s}^{-1}$ is obtained for the Casson rheological model.

The presented analysis of measured shear stress allows making the assumption that the increase of solids concentration from $10.12 \%$ up to $18.28 \%$ allows transporting more solids particles without significant declining fluent character of the described slurry. The effect of solids concentration on the shear stress for lime slurries with chosen solids concentration is shown in Figure 8. 


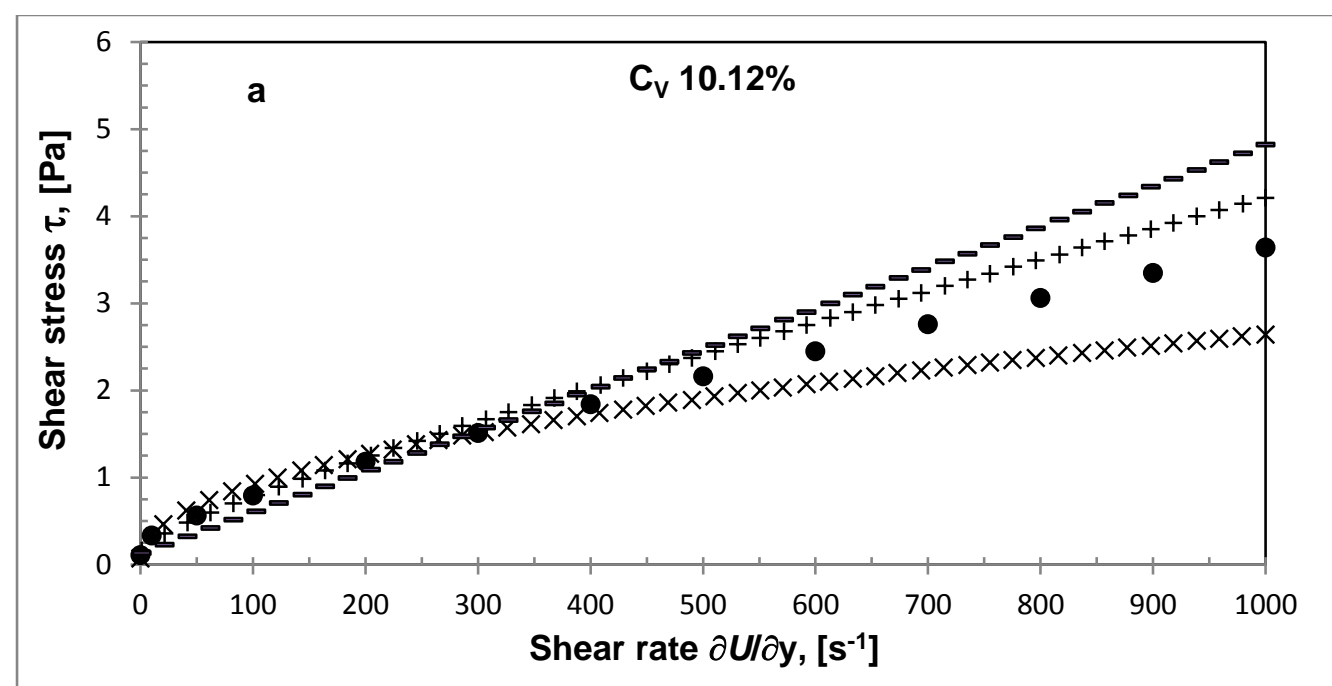

- experiment $\times$ Herschel-Bulkley's model +Casson's model -Bingham's model

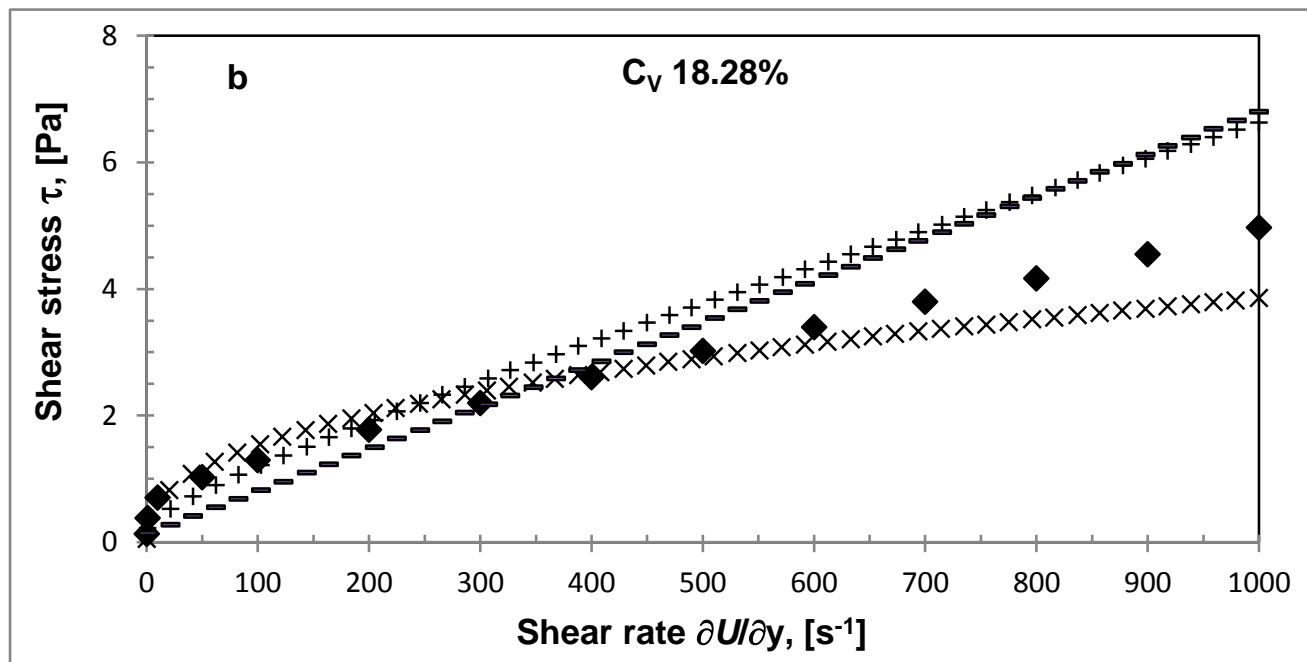

- experiment $\times$ Herschel-Bulkley's model + Casson's model -Bingham's model

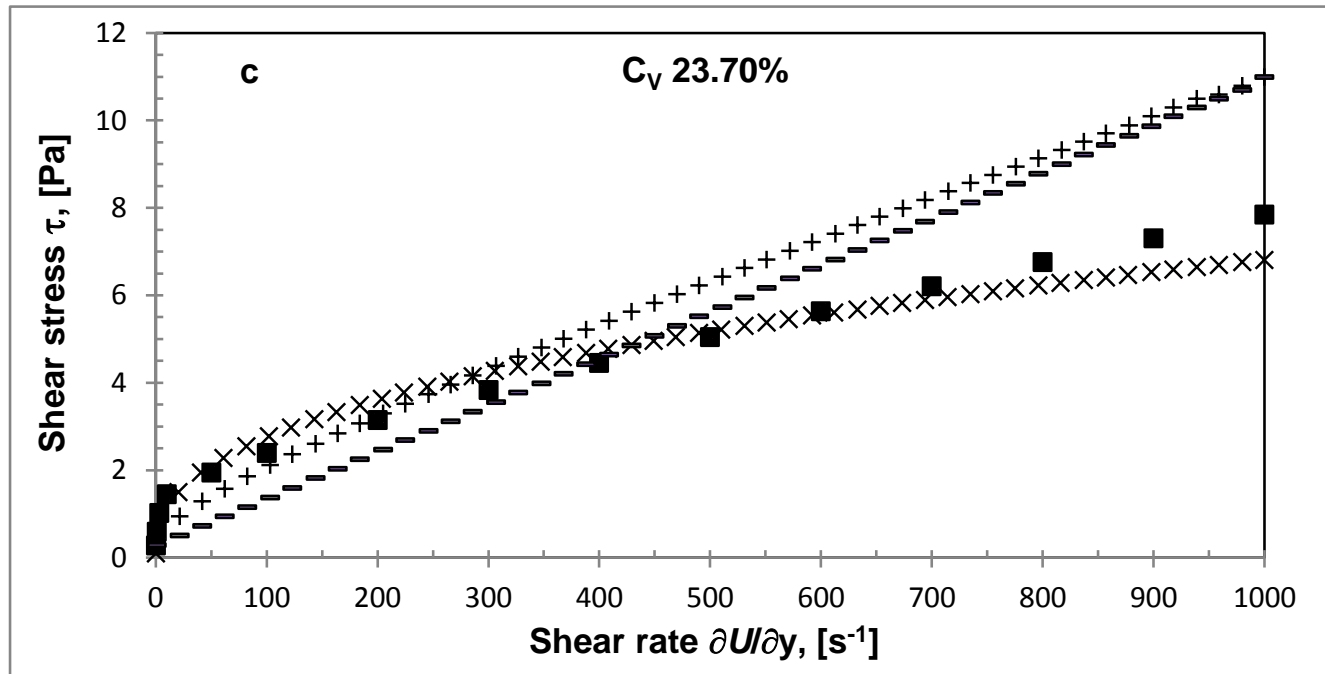

- experiment $\times$ Herschel-Bulkley's model +Casson's model -Bingham's model

Fig. 7 Results of measurements and calculations of shear stress for lime slurries with solids concentration by volume equal to: a) $\mathrm{C}_{\mathrm{v}}=10.12 \%$, b) $\mathrm{C}_{\mathrm{v}}=18.28 \%$ and c) $\mathrm{C}_{\mathrm{v}}=23.70 \%$ 


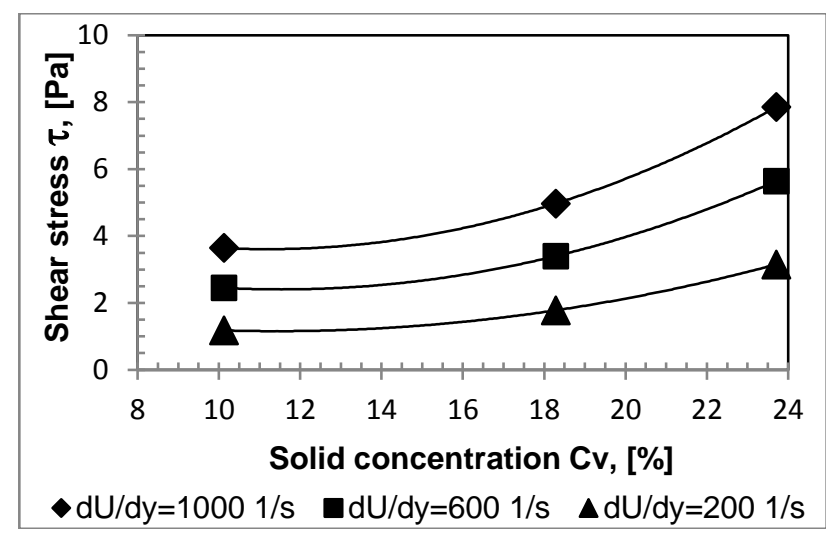

Fig. 8 Effects of solids concentration on the shear stress in fine-dispersive lime slurry

As we can see in the graph, for slurries with solids concentration below $18.28 \%$ by volume, the shear stress increases moderately with increasing solids concentration, whereas for slurries with solids concentration above $18.28 \%$ by volume the shear stress increases exponentially. Therefore, it can be stated that the increase of solids concentration in pumping slurry from $10.12 \%$ to $18.28 \%$ by volume improves effectiveness of the process without exposing the installation to downtimes or malfunctions of the pressure pump. Furthermore, increasing the concentration of the pumped slurry affects the consumption of water and electricity in the hydrotransport. Reducing the amount of process water circulating in the production cycle also results in savings on earlier elements of the industrial installation. Such savings, in overall, balance the influence on reducing total costs of the production process.

\section{Conclusions}

The analysis presented in the paper showed positive effects of lime slurry mass concentration increasing the improvement of the hydrotransport process efficiency. The results of the performed rheological analysis indicate that it is possible to pump a medium with almost twice as higher solids concentration with a lower volumetric flow rate, without a significant increase in electricity consumption by the pump or the pump system. The positive aspect of the proposed solution application translates into the increase in the efficiency of the entire production process. Reducing the amount of water circulating in the production cycle results in savings also on the earlier elements of the industrial installation, not included in the analysis. The effect of the proposed solution is also the reduction in the pollution rate of industrial ponds, which is a measurable ecological effect.
References:

[1] BeltrĂ n-Prieto J. C., KolomaznĂk K., Determination of Amount of Theoretical Zones and Feed Location in Multicomponent Distillation, WSEAS Transactions on Applied and Theoretical Mechanics, Vol. 14, 2019, No. 22, pp. 198-204.

[2] Ćerny V., Drochytka R., The Influence of Different Types of Siliceous Raw Materials on Tobermorite Formation in Lime-Silica Composite, WSEAS Transactions on Environment and Development, Vol. 15, 2019, pp. 57-64.

[3] Charles M. E. and Charles R. A., Advances in solid-liquid flow in pipes and its applications, Pergamon Press, New York, 1971.

[4] Shook C. A. and Roco M., Slurry Flow: Principles and Practice, Boston: ButterworthHeinemann, 1991.

[5] Bartosik A., Simulation and experimental studies of axially-symmetrical flow of fine- and coarse-dispersive slurry in delivery pipelines, Ed. Kielce University of Technology, 2009.

[6] Chhabra R. and Richardson J., Non-Newtonian flow in the process industries, ButterworthHeinemann, Oxford, 1999.

[7] Ghosh T. and Shook C. A., 1990, Freight pipelines, ed. H. Liu and G. F. Round, Hemisphere, New York, 1990.

[8] Kembłowski Z., Non-Newtonian fluid rheometry, Scientific and Technical Publishing, Warsaw, 1973.

[9] Senapati P. K., Panda D. and Parida A., Predicting viscosity of limestone-water slurry, Journal of Minerals \& Materials Characterization \& Engineering, Vol. 8, No. 3, 2009, pp. 203-221.

[10] Bartosik A., Simulation of turbulent flow of fine dispersive slurry, Chemical Process Engineering, Vol. 31, 2010, pp. 67-80.

[11] He M., Wang Y. and Forssberg E., Slurry rheology in wet ultra-fine grinding of industrial minerals: a review, Powder Technology, Vol. 147, 2004, pp. 94-112.

[12] Ohlan R., Gopaliya M. K. and Kaushal D. R., Simulation of sand-water slurry flows through pipeline, Multiphase Science and Technology, Vol. 30, No. 1, 2018, pp. 293-318.

[13] Dziubiński M., Kiljański T. and Sęk J., Theoretical foundations and rheology measurements methods, Ed. Lodz University of Technology, 2014.

[14] Heywood N., Flow curve measurements for process engineering design applications, $7^{\text {th }}$ 
Southern African Society of Rheology Conference Paper, Stellenbosch, 2018.

[15] Senapati S., Pothal J. K., Some studies on rheological and pipeline transportation of concentrated limestone-water slurry, International Journal of Fluid Mechanics Research, Vol. 44, No. 4, 2017, pp. 349-356.

[16] Kaushal K., Satish K., Ajay K., Effect of additives on static settled concentration, $\mathrm{pH}$ and viscosity of bottom ash-water suspension, Journal of Mechanical Engineering, Vol. 68, No. 3, 2018, pp. 49-58.

[17] Jaworska B. and Bartosik A., Influence of deflocculant on shear stress in hydromixture flow, Journal of Physics: Conference Series, 1101: 012010, 2018.

[18] Peker S. M. and Helvaci S. S., Solid-liquid two phase flow, Elsevier: Amsterdam, 2008.

[19] Senapati P. K. and Mishra B. K., Rheological characterization of concentrated jarosite waste suspensions using Coutte \& tube rheometry techniques, Powder Technology, Vol. 263, 2014, pp. 58-65.

[20] Krupicka J. and Matousek V., Gamma-raybased measurements of concentration distribution in pipe flow of settling slurry: vertical profiles and tomographic maps, Journal of Hydrology and Hydromechanics, Vol. 62, No. 2, 2014, pp. 126-132.

[21] Vlasak P., Matousek V., Chara Z., Krupicka J., Konfrst J. and Kesely M., Concentration distribution and deposition limit of mediumcoarse sand-water slurry in inclined pipe, Journal of Hydrology and Hydromechanics, Vol. 68, No. 1, 2020, pp. 83-91.

[22] Bartosik A., Simulations of frictional losses in a turbulent blood flow using three rheological models, WSEAS Transactions on Fluid Mechanics, Vol. 15, 2020, pp. 131-139.

[23] Kiljański T., Dziubiński M., Sęk J. and Antosik $\mathrm{K}$., The use of fluids rheological properties measurements in engineering practice, Warsaw: EKMA, 2009.

[24] Rushd S., Hassan I., Sultan R. A., Kelessidis V. C., Rahman A., Hasan H. S. and Hasan A., Terminal settling velocity of a single sphere in drilling fluid, Particulate Science and Technology, 2018.

[25] Schramm G., A practical approach to rheology and rheometry, Gebrueder Haake, Karlsruhe 1994.

[26] He M., Wang Y., Forssberg E., Parameter studies on the rheology of limestone slurries, International Journal of Mineral Processing, Vol. 78, No 2, pp. 63-77.
[27] Michaels A. S. and Bolger J. C., Settling rates and sediment volumes of flocculated Kaolin suspensions, Journal of Industrial and Engineering Chemistry Fundamentals, Vol. 1, No. 1, 1962, pp. 24-33.

\section{Creative Commons Attribution \\ License 4.0 (Attribution 4.0 \\ International , CC BY 4.0)}

This article is published under the terms of the Creative Commons Attribution License 4.0 https://creativecommons.org/licenses/by/4.0/deed.en US 